\title{
Türk Telekom Bünyesindeki Uygulama Destek Ekipleri İçin Olay Çözüm Süresini Kısaltmaya Yönelik Yardımcı Uygulama Geliştirme
}

\author{
Fulden Neoman, Çiğdem Tarhan*
}

öz

Türk Telekom bünyesinde yer alan uygulamalar, birbirine bağlı karmaşık entegrasyonlardan oluşan bir yapıya sahiptir. Türk Telekom'un sunduğu ürünler için süreçlerin tamamına yakını birden fazla uygulama üzerinden işlemektedir. Bu yapı nedeniyle, destek verilen uygulamalarda, sürecin kontrolünü sağlamak için ilgili sorun kaydının birden fazla destek takımı tarafindan incelenmesi gerekmektedir. Bu durum; ilgili kaydın çözüm süresini uzatmakta, birimler arasındaki bă̆ımlılı̆̆ artırmakta ve sorunun çözülmesini geciktirmektedir. Mevcut işleyişte ise ekiplerin olay kayıtlarını yönlendirmeden diğer ekiplerin veri tabanında tuttukları bilgileri çekebildikleri bir platform bulunmamaktadır. Bu çalışmada; operasyon terminolojisi ile "olay çözüm süresi” ni, bir başka deyişle de iş yapma süresini iyileştireceği iddia edilen "EntegreAsisTT” uygulaması geliştirilmiştir. Geliştirilen uygulama, destek ekipleri tarafindan birbirlerinden en çok talep ettikleri bilgileri bir araya getirerek tek bir arayüzden sunmaktadır. Ekipler, servis masası üzerinden açılan olay kayıtlarını diğer ekiplere yönlendirmek yerine bilgi gereksinimlerini bu uygulama üzerinden karşılayabilecektir. Bu sayede olay kayıtlarında hızlı aksiyon alınması sağlanarak olası şikayetlerin önüne geçildiği saptanmıştır.

Anahtar Kelimeler: Telekom, Olay Yönetimi, Uygulama Geliştirme, Scrum Tekniği, Visual Studio.

\section{Development of a Utility Application for Shorten Solution Time of Tickets to Software Support Department in Turk Telecom}

\begin{abstract}
The applications within Türk Telecom have a structure composed of interconnected complex integrations. Due to this structure, in supported applications, the relevant issue report must be examined by more than one support team in order to ensure control of the process. This situation extends the relevant report's solution period, increases the dependence between units and delays the solution of the issue. As for the current process, there is an absence of a platform in which teams can pull information other teams have kept in databases without redirecting the event reports. In this study; the "EntegreAsisTT" application alleged to enhance the work period-in operation terminology "the event solution period" was developed. The developed application combines information that support teams request from each other and presents them from a single interface. Thus potential complaints can be prevented by taking fast action with event reports.
\end{abstract}

Keywords: Telecom, Event Management, Application Development, Scrum Tecnique, Visual Studio.

Information of Author(s):

Fulden Neoman

ORCID: 0000-0002-9601-0929

fuldenneoman@hotmail.com

Çiğdem Tarhan

ORCID: 0000-0002-5891-0635

cigdem.tarhan@deu.edu.tr

Dokuz Eylül University, Department of Management

Information Systems

ISTANBUL

UNIVERSIT Y

UN

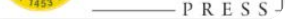

(*) Contact Author
DOI: 10.30801/acin.362171

Submit Date:

05.12 .2017

Accept Date:

11.07.2018

Publish Date:

21.12.2018

Address: Dokuz Eylül University, Department of Management Information Systems, İzmir, Turkey

Telephone Number: +90 2323010762 


\section{GİRIȘ}

Yirminci yüzyılın son çeyreğinden itibaren başlayan ve halen yaşamakta olduğumuz "bilgi çağı"; firmalar, müşteriler, müşterilerin ihtiyaç ve beklentileri açısından şirketlerin başarı ve rekabet gücü kazanmaları için yeni teknolojilerin fiziksel değer haline dönüşüm sürecini hızlandırmıştır. Günümüzde firmaların başarılı ve sürdürülebilir bir geleceğe sahip olabilmeleri için bilginin, gelişmiş ve yeterli iletişim sistemleri aracillğıyla paylaşılıp işlenmesiyle doğrudan bağlantılıdır. Bu süreçte, internetin çok kısa bir sürede ve etkin bir biçimde, geniş bir alanda bilginin dolaşımını sağladığı görülmektedir (Altun, 2006). İnternet teknolojilerinin en büyük avantajı, iletişim ve bilgi transferi maliyetlerini düşürerek, erişim kapasitesini ve hızını arttırması ve daha zengin içerikli bilgiye ulaşma imkânı sağlamasıdır (Cyberethics, 2015). Özellikle otomasyon, bilgisayar teknolojileri ve işletmelerin diğer bilgi ve haberleşme teknolojilerini kullanması önemli ölçüde artmış ve gerekli hale gelmiştir. Teknolojiye uyum sağlamak günümüz modern toplumlarında, işletmeler ve bireyler için önemli bir sorun teşkil etmektedir (Oktav ve diğ., 1990; Aydın, Tarhan ve Tecim, 2015).

Yirmi birinci yüzyılda, haberleşme ve bilgisayar teknolojilerinin birleşmesiyle olağanüstü bir gelişme gösteren telekomünikasyon hizmetleri uygun altyapı sağlandığı takdirde dünyanın her noktasındaki bilgi kaynaklarına erişebilme ve bilgiyi transfer edebilme imkânı sunmaktadır (Çakal, 1996). Dünyada yaşanan teknolojik gelişmelerle beraber bilginin önemi oldukça artmıştır. Bilgiye daha kolay erişebilen toplumların sosyal ve ekonomik anlamda daha hızlı kalkındıkları açıkça görülmektedir. Bu durum da bilgi aktarımı için gerekli altyapıyı sağlayan telekomünikasyon sektörüne verilmesi gereken önemi vurgulamaktadır. Ülkemizde Türk Telekomünikasyon Anonim Şirketi (Türk Telekom) yerel operatör olarak; bünyesinde bulunan alt birimlerle telekomünikasyon hizmetlerinin ülke genelinde yaygınlaştırılmasından sorumludur. Telekomünikasyon hizmetlerinin işletilmesi, müşteriye ulaştırılması, gerekli altyapının kurulmasında Telekom Müdürlükleri oldukça önemli bir role sahiptir (Türk Telekom Veri Merkezi, 2015).

Günümüzde Türk Telekomünikasyon sektörü içinde yaşanan, son ylllarda meydana gelmiş büyük gelişmeler ve telekomünikasyon sektörü ile ilişkili tüm sektörler arasındaki rekabet ortamının fazla olması; bu sektörün ülke ekonomisi için çok önemli bir değer haline geldiğini açık bir şeklide gözler önüne sermektedir (Beyler, 2014). Bu sektör bireysel haberleşmeyi sağlamanın yanı sıra toplumun temel altyapısını oluşturan ve başka sektörlerin gelişmesine katkı sağlayan dinamik bir alandır (Ekergil, 2005). Bunun yanı sıra; Türk Telekom mevcut altyapısı ile pazardaki en yüksek bant genişliğine sahiptir. Bu da veri trafiğinin çok hızlı gerçekleşmesini sağlamaktadır. Türk Telekom Veri Merkezi, müşterilerine Sunucu Barındırma, Sunucu Kiralama, BuluTT Sunucu, E-Posta ve Web Alanı Barındırma ve Güvenlik gibi hizmetleri Ankara ve İstanbul olmak üzere iki bölgede sunmaktadır (Türk Telekom Veri Merkezi, 2015).

Tüm bu iş süreçleri içerisinde Türk Telekom'a çeşitli alanlarda destek veren farklı firmalar bulunmaktadır. Public Switched Telephone Network (PSTN), Digital Subscriber Line (DSL), Turk Telecom Virtual Private Network (TTVPN), Naked Digital Subscriber Line (NDSL), Very High Speed Digital Subscriber Line (VDSL), Naked Very High Speed Digital Subscriber Line (NVDSL) gibi ürünler için operasyon ve danışmanlık desteği müteahhit firma tarafından verilmektedir. Türk Telekom'a operasyon konusunda destek veren müteahhit firmanın operasyon yönetimi Ankara ve İzmir ofisleri tarafından gerçekleştirilmektedir. Ankara'daki ekipler Türk Telekom binasında Türk Telekom'un domaininde çalışabilmektedir. Bunun yanı sıra İzmir ekipleri ise Virtual Private Network (VPN) ile sistemlere giriş sağlamaktadır.

İşletmelerin günümüzün rekabetçi ve değişken dünyasında ayakta kalabilmesi için, rekabetçi stratejiler geliştirip bu stratejileri de günün koşullarına uygun olarak çabuk adapte edilebilecek şekilde esnekleştirmeleri gerekmektedir (Demirhan, 2002). Operasyon ekiplerinin, Ön Destek Ekibi tarafından açılan olay kayıtlarını müşteri odaklılığın gereği olarak gün içerisinde çözüme ulaştırması önem taşımaktadır.

\section{OPERASYON EKİPLERİ ORGANIZASYON YAPISI: OLAY YÖNETİMI}

Türk Telekom personeli tarafindan telekomünikasyon sistemlerinde yaşanan sorunların veya bilgi taleplerinin iletilmesi Ön Destek Ekibi'ne açılan Servis Masası kayıtları üzerinden yapılmaktadır. Ön Destek Ekibi, taraflarına iletilen kayıtlar için anlık çözümler üretir. Açılan bu kayıtlarda çözüme ulaşılamaması durumunda "çağrı" kaydı 
"Seviye 2 Ekipleri” tarafından ele alınmak üzere "olay" kaydına çevrilir. Bu sorumluluk çerçevesinde "olay yönetimi” olarak adlandırılan bu sistem ürün/uygulama/servislerin beklenen şekilde ve kesintisiz olarak çalışmasını hedeflemektedir.

Seviye 2 Ekipleri, müteahhit firma bünyesinde çalışan ve Türk Telekom tarafına operasyon konusunda destek veren operasyon destek üyeleridir. Bilgi Teknolojisi Altyapı Kütüphanesi süreçleri çerçevesinde tanımlanan Seviye 2 kapsamında yürütülen operasyon hizmetinin işleyişini düzenlemek, yürütmek, iyileştirmek ve Hizmet Düzeyi Sözleşmesi [Service Level Agreement (SLA)] sınırları içinde mümkün olan en iyi hizmeti sağlamak olay yönetiminin amaçları arasındadır. SLA ise Türk Telekom ile müteahhit firma arasında, verilen hizmetin hangi seviyede verilmesi gerektiğinin belirlendiği bir sözleşmedir. Türk Telekom Uygulama Destek Müdürlüğü için verilen hizmet seviyesi, “olay”ın açılması ile olay yönetimi iş akışının işletilmesinin ardından sonuçlandırılmasına kadar geçen süredir. Türk Telekom bünyesinde yürütülen operasyon destek hizmetinin Seviye 1, Seviye 2 ve Problem Destek ekipleri çerçevesindeki şematik gösterimi Şekil 1'de yer almaktadır.

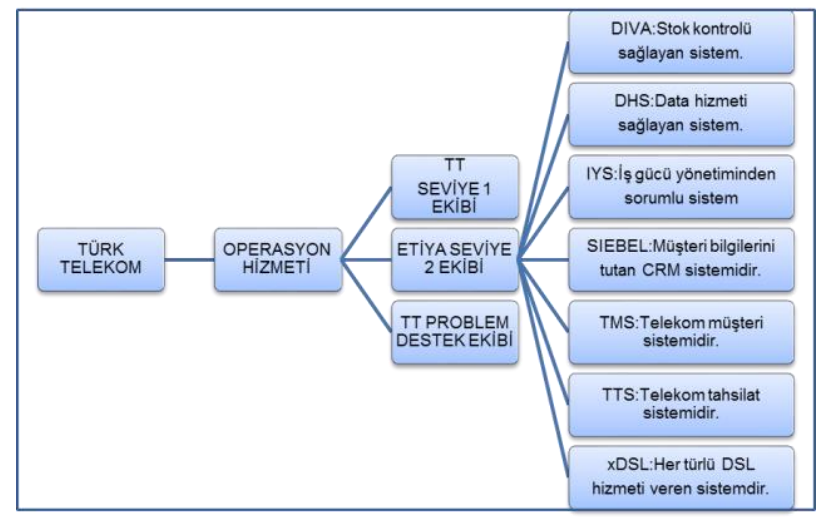

Şekil 1. Operasyon Destek Süreci

Olay yönetimi, verilen hizmeti kesintiye uğratan veya kesintiye uğratabilecek durumları kapsar. Bu durumlar Türk Telekom kullanıcıları aracılığıyla olabildiği gibi Seviye 1 kapsamında çalışan Ön Destek Ekibi tarafından da HPSM kullanılarak iletilen durumlardır. Ön Destek Ekibi’ne gelen sorunlar/talepler “çağrı" olarak nitelendirilirken, Ön Destek Ekibi’nin çözüm bulamadığ 1 “çağrı”lar, sınıflandırma yapıldıktan sonra ilgili gruba atanmalarıyla "olay” ismini alır. Olay yönetim süreci, çağrının olay olarak tanımlanmasıyla başlar ve ilgili olayın çözülerek kapatılmasıyla sona erer.

Olayların, tanımlanan SLA sınırları içinde çözümünün gerçekleştirilmesi ve kapatılması önem teşkil etmektedir. $\mathrm{Bu}$ doğrultuda operasyon hizmetinin önceliği daha hızlı ve doğru biçimde destek vermek olup bunun gerçekleşmesi için ekipler arası koordinasyonun güçlü olması gerekmektedir. Ön Destek Ekibi’nden iletilen kayıtlar, Seviye 2 Ekipleri olarak adlandırılan “İş Gücü Yönetim Sistemi (IYS), Her türlü Sayısal Abone Hattını Yöneten Sistem (xDSL), Türk Telekom Müşteri Sistemi (TMS), DİVA, Data Hizmet Sistemi (DHS), Türk Telekom Tahsilat Sistemi (TTS), PROGRAM 1 (SIEBEL)" ekiplerine yönlendirilmektedir. Bu ekipler tarafindan süreçlere dair bilgi paylaşımıyla sorunlar giderilmeye çalışılmaktadır.

Gün içerisinde açılan olay kayıtların birden fazla ekibin incelemesine gereksinim duyabileceği düşünüldüğünde çözüm süresinin uzaması kaçınılmazdır. Olay kayıtlarındaki çözümün gecikmesi de şikayetlere sebep olmaktadır. $\mathrm{Bu}$ şikayetler maddi ve manevi olarak şirketi olumsuz yönde etkilemektedir. Ayrıca sadece bilgi talep etmek için yönlendirilen belirli tipteki kayıtların sayıca fazla olması ekiplerin iş yükünü artırmaktadır. Bu problem tespitinin akabinde sistem için bir uygulama önerisi planlanmıştır.

Çalışma kapsamında geliştirilen uygulama her durum için değil en sık talep edilen bilgi gereksinimleri analiz edilerek geliştirilmiştir. Uygulamanın sınırını bu çerçeve oluşturmaktadır. Bunun yanı sıra dinamik bir yapıya sahip olan operasyon destek sürecinde değişim kaçınılmazdır. Günümüz bilişim teknolojilerindeki zaman ile değişen süreçte talep edilen bilgiler, ekiplerin görev tanımları kapsamında farklılaşmalar gösterebilir. 


\section{INFOั}

ISSN: 2602-3563

Çalışmanın hipotezi, geliştirilen uygulama ile farklı ekipler arasındaki bilgi talebi gereksinimini azaltarak gün içerisinde açılan olay kayıtlarında gerekli aksiyonların hızlı bir şekilde alınmasını sağlamaktır. Amaçlar, BTK şikayetlerinin önüne geçmek, olay kayıtlarının çözüm sürelerini kısaltmak ve ekipler arası işleyiş hakkında bilgi sahibi olunmasını sağlayarak rotasyon uygulamasını daha etkin hale getirmektir.

\section{YÖNTEM}

Uygulama geliştirmek için; operasyon ekiplerine açılan olay kayıtlarının türleri ve gün içerisindeki açılma sıklıkları analiz edilmiştir. Analiz aşamasında, bu kayıtların en yoğun olarak geldiği ve iş yükleri diğer ekiplere oranla daha fazla olan ekipler için geliştirilmesi planlanmıştır. Uygulama içerisindeki modüllerin kullanılabilirliğinin fazla olması adına veri düzeltmesi gerektirmeyen, kronik hale gelen bilgi taleplerinin karşılanması öngörülmüştür. Bu sayede kronik durumda olan olay kayıtları için aksiyonun alınacağı ekip tarafından farklı bir ekibe yönlendirme yapılmadan sonuçlanmasını sağlayan bir platform hedeflenmiştir.

Modüller xDSL, TMS, IYS, TTS ekipleri için geliştirilmiştir. Ekip başına düşen olay kayıt sayısı aylık olarak en fazla olan ve ekipler arası olay kaydı yönlendirmesi yoğun şekilde yaşanan dört ekip seçilmiştir. Ekiplere açılan aylık ortalama olay kayıt sayıları xDSL(2600), TMS(2450), IYS(1200), TTS(700)'dür.

Geliştirilecek olan uygulamada dört ana ekip belirlendikten sonra her ekibin kronik hale gelmiş olan problemleri saptanmıştır. Bir ekibe açılan olay kayıtları hangi ekip bilgisine ihtiyaç duyarsa o ekip için hazırlanmış modül altından sorgulama yapabileceği ve aksiyon alabileceği modüller için koşu gereksinim setleri hazırlanmıştır. Hazırlanan bu gereksinim setleri sayesinde ürün gereksinim setinin şablonu belirlenmiştir.

Operasyon hizmetinin organizasyonel yapısı gereği tüm ekipler birbirleri ile iletişim halinde olmak durumundadır. Olay yönetim sürecinin kesintisiz şekilde yürütülebilmesi için her ekibe açılan olay kayıtlarının gerek farklı ekibe iletilerek gerekse çözümlenerek kapatılması gerekmektedir. Her ekip bünyesinde Oracle veri tabanı üzerinde tutulan şemaları ve içerikleri farklıdır. Bu içerikler ile ekiplerin bilgi ihtiyaçları karşılanır. Her ekibe ait özel bilgilerinin tutulduğu veri tabanlarının farklı olmasından kaynaklı ekipler arasında köprü oluşturması planlanan bir uygulama geliştirilmiştir. Bu uygulama ile ekipler, diğer ekibe yönlendirme yapmadan olay kayıtlarını çözüme ulaştıracaktır.

Uygulamayı kullanmanın yöntemi şu şekildedir;

- Olay kaydının açıldığı ekip, kendi tarafında çözümün varlığını kontrol eder.

- Çözüm uygulamasına başlamak için farklı ekipten bilgi talep etmesi gerektiği durumlarda bu bilginin geliştirilen uygulamada var olup olmadığı tespit edilmeye çalışılır.

- İstenilen bilgiye erişim sağlanabiliyor ise Oracle veri tabanı üzerinden giriş yapılan modül ile veri tabanına bağlantı yapılır ve bilgiye ulaşılır.

Yazılım geliştirme sürecinde gereksinimlerin erken tespit edilmesinin önemi büyüktür. Geliştirilecek olan projenin belirlenen amaçlar doğrultusunda tamamlanması ve zamanında bitirilmesi gerekmektedir. Teknolojinin çok hızlı gelişmesiyle birlikte yeniliklerin projeye uygulanabilir olması oldukça önemlidir. Zaman içerisinde proje yönetiminin daha zor ve karmaşı hale gelmesinden dolayı yazılım geliştirme metodlarından faydalanmak uygulamanın işleyişi açısından kolaylık sağlayacaktır (Hazer, 2008). Geliştirilen yazılım projelerinin müşteri gereksinimlerini karşılayamadığı, istenilen hedefi tam olarak gerçekleştiremediği ve zamanında bitirilemediği görülmektedir (Baytam, 2011). Projenin başarısızlık ihtimalinin önüne geçmek için yazılım geliştirme ortamlarına uygun olarak tasarlanmış yazılım geliştirme yönetim modelleri bulunmaktadır (Demiroğ, 2012). Bu metodlardan olan Çevik Yaklaşım, yazılım geliştirme safhasında geç ortaya çıkan gereksinim değişimlerini çabuk karşılamayı esas alan yöntemlere verilen genel bir isimdir. Çevik metodlardan en fazla ön plana çıkanlar Scrum, Dynamic Systems Development Metodology (DSDM), Adaptive Software Development (ASD) ve Extreme Programming (XP)'dir (Karlıdere ve Kalıpsız, 2003). Çevik yaklaşımların değişen koşullara en kısa sürede yanıt verir nitelikte olması, bu yaklaşımların planlamadan çok değişim isteklerinin karşılanabilmesini önemli kılmaktadır. 
Uygulamanın modülleri oluşturulurken kullanılan Scrum Tekniği; belirli zaman dilimleri halinde ilerleyen, kısa döngülerle çıtı üretme ve geri bildirim düşüncesine dayanan, esnek ve prensipleri olan yazılım geliştirme metodudur (Demir, 2015). Bu teknik ile yazılım iteratif olarak yürütülmekte ve bu sayede verimli bir kaynak yönetimi sağlanmaktadır (Demiroğ, 2012). Yaklaşımdaki esneklik projede meydana gelebilecek olan değişimlerin zaman ve performans kriterlerini olumsuz yönde etkilemesinin önüne geçebilmektedir. Bu olumsuzlukların önüne geçebilmek, yazılıma odaklanmayı ve değişiklik taleplerinin karşılanmasını sağlamaktadır (Şahin, Kaynak ve Koç, 2013).

Her bir yöntemin stratejisi farklı olmakla birlikte yazılım geliştirme süreçleri analiz, tasarım, kodlama, test ve onarım sırasını izler. Yöntemlerin esnek olmayışı, yapılacak her işin kesin tanımlı bir sırasının oluşu, kimlerin hangi işlerden sorumlu olduğunun kesin ve katı çizgilerle belirlenmiş olması ve geliştirim sırasında grup içi ve müşteri ile iletişimin yeterli olmayışı geleneksel yöntemlerin en önemli sorunlarındandır (Süloğlu, 2005).

Projelerin başlangıçtaki gereksinimlerinin \%35 oranında değişebildiği ve teknolojinin hızla gelişmesi halinde bu duruma uyum sağlamanın sorun yaratmakta olduğu ve de sürecin önceden tahmin edilemez şekilde farklılaşmalar gösterdiği söylenmektedir. Dolayısıyla, çevik yöntemler ağırlıklı olarak yazılım geliştirme projelerinde kullanılsa da esnek yapısı sayesinde her türlü projede uygulanabilir bir metodolojidir. Başarı oranları geleneksel yöntemlere göre daha yüksek olduğu ortaya konmuştur. Ayrıca, çevik yöntemlerin kullanıldığı projeler sadece daha başarılı olmakla kalmayıp değişen ihtiyaçlara daha hızlı yanıt vererek riskleri en aza indirmekte ve daha kaliteli ürünler sunmaktadır (Atmaca, 2012).

Kullanılan bu teknik sayesinde çalışmamız parçalar halinde ele alınmıştır. Parçalar her bir modülü simgelemektedir. Bir sprint bittiği zaman çalı̧ır bir uygulama elde edilmiştir. Biten modülün akabinde testler gerçekleştirilmiş̧ir. Test senaryoları sonucunda ortaya çıkan hatalar, eksiklikler giderilmiş̧ir. Kısa aralıklarla yazılıma ait sprintler teslim edildiği için geri beslenim (feedback) sağlanmaktadır (Yazılım Her Yerde, 2014). Böylece bir sonraki modül üzerinde yapılan çalışmaların gözleme dayalı olarak daha şeffaf ve adaptasyonu yüksek bir şekilde devam ettiği saptanmıştır.

Scrum Tekniği ile diğer modüllerin geliştirilmesinin başlangıç ve bitiş süreleri açısından tahminlenmesi kolaylaşmıştır (Agile, 2015). Ayrıca, bu tekniğin kullanılması karmaşık olan projenin daha kurallı ve basit olarak sürdürülmesine olanak tanımıştır. Scrum Tekniği sayesinde, çalışma kapsamında kullanılan teknik ve kuralların bütünlügü tüm modüllerin aynı çerçeve içinde geliştirilmesini sağlamıştır. Böylece öngörü ile riski kontrol etme olanağı doğmuştur. Bu sayede çalışmanın belirtilen zaman çerçevesinde bittiği görülmektedir.

Dört ana modül olarak planlanan uygulamada, test süreçleri daha etkin ve seri bir biçimde gözlenebilmiştir. Geliştirilen her modül için test senaryoları gerçekleştirilerek bir sonraki modüle geçmeden önce çalışabilir bir uygulama elde edilmiştir.

\section{Yazılım Geliştirilmesi:}

C\# programlama dili kullanılarak geliştirilen yardımcı uygulama ile her ekip ihtiyaç duyduğu bilgiye elinde var olan veriler ile ulaşabilmektedir. Geliştirme ortamı olarak Microsoft Visual Studio kullanılmıştır. Geliştirilen uygulama istemci olarak tasarlanmıştır. Uygulama çalıştırıldığında ilgili veri tabanına bağlanarak gerekli işlemler yerine getirilmektedir. Uygulamanın kullanılabilmesi için gereksinimler aşağılda belirtildiği gibidir;

- DSL veri tabanına bağlanabilen kullanıcı

- TMS veri tabanına bağlanabilen kullanıcı

- IYS veri tabanına bağlanabilen kullanıcı

- $\quad$ TTS veri tabanına bağlanabilen kullanıcı

- .NET Framework

- Oracle Client 11g 
İlk olarak uygulamanın arayüzü oluşturulmuştur (Şekil 2). Her bir ekran Scrum Yöntemi kapsamında adım adım tasarlanmıştır. Kodlama safhasına geçildiğinde tekrarlayan durumlar için gereksiz yer kaplama sorununun önüne geçilmesi adına ayrı ayrı form açmak yerine tek bir form üzerinden işlem yapılmıştır. Bu sayede aynı işin birden fazla yapılması engellenmiştir. Tekrarlayan durumları tek bir formda toplayan kod örnekleri aşağıda verilmektedir. Visual Studio ortamında veri tabanı bağlantıları tek bir veri tabanı sınıfı altında tutulmuştur. Entegrasyonlardan biri seçildiğinde koda gömülen TNS ayarları ile bağlantı sağlanmaktadır.

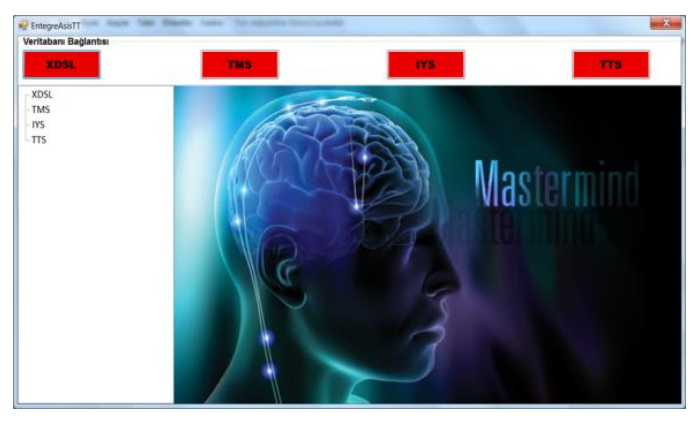

Şekil 2. Uygulama Ara Yüzü Giriş Ekranı

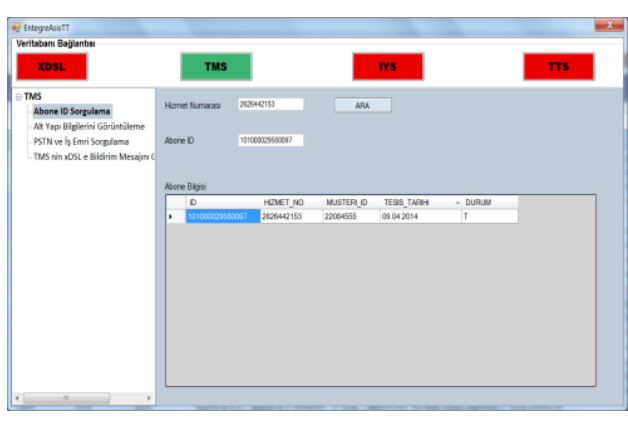

Şekil 3. Uygulama Kullanıcı Ekranı

\section{Uygulama Gelişstirme Platformunun Seçilmesi}

Microsoft Visual Studio, Microsoft tarafindan geliştirilen bir tümleşik geliştirme ortamı [Integrated Development Environment (IDE)] olarak nitelendirilmektedir (MEB, 2012). Microsoft Windows, Windows Mobile, .NET Framework, .NET Compact Framework ve Microsoft Silverlight tarafından desteklenen tüm platformlar için yönetilen kodların yanı sıra yerel kod ve Windows Forms uygulamaları, web siteleri, web uygulamaları ve web servisleri ile birlikte konsol ve grafiksel kullanıcı arayüzü tasarlanabilmektedir (Vikipedi, 2015). Visual Studio, farklı programlama dillerini desteklemesinin sayesinde kod editörü ve hata ayıklayıcısı neredeyse tüm programlama dillerinde kullanılabilmektedir. Dahili diller C/C++, Visual Basic .NET üzerinden (VB .NET), C\# (Visual C\# ile), ve F\# (Visual Studio 2010 itibariyle) içermektedir. Otomatik tamamlama önerileri, modsuz bir liste kutusu içerisinde, kod editörü üzerinden açılmaktadır. Kullanım kolaylığı ve farklı dillerin kullanılabilmesi sebebiyle Microsoft Visual Studio tercih edilmiştir. Bunun yanı sıra XML bilgisini desteklediği için uygulamada sıklıkla sorgulanacak olan mesaj bilgilerinin sorgulanmasını sağlamıştır.

.NET Framework ise bileşen yönelimli uygulamaların geliştirilmesini destekleyen bir ortamdır. Farklılık gösteren bilgisayar dillerinin bir arada çalışmasını mümkün hale getiren bir platformdur. Windows platformu için güvenlik, taşınabilirlik ve ortak bir programlama modeli sağlar. .NET sınıf kütüphanesi de programlama amacı ile geliştirilmiştir. Bu kütüphane, programın çalışma ortamına erişmesine izin vermektedir (Oral, 2012).

\section{Koşu Gereksinim Setlerinin Test Edilmesi:}

Yazılım geliştirme sürecinde ortaya çıkabilecek olumsuzlukların giderilmesi adına sistem test edilmesi gerekmektedir. Statik ve dinamik test tekniği olmak üzere iki çeşit yazılım test tekniği mevcut olup dinamik test tekniği 5 farklı teknik olarak gerçekleştirilmektedir (Öztürk, 2012). Sistemin geliştirilmesi aşamasında Scrum Tekniği uyarınca modüller sprintler olarak ele alınmıştır. Dolayısıyla, her biten modülün ardından diğer modüle geçilmeden test edilmesi sağlanmıştır. Her biten modülün ardından kara kutu test tekniği kullanılarak modülün gereksinimleri karşılama koşulları ele alınmıştır. Gereksinimlerin gerçekleşmediği durumlar "olumsuz" olarak nitelendirilmiş ve istenilen durum gerçekleşmesi için modüller tekrar ele alınıp düzeltilmiştir.

\section{BULGULAR}

Geliştirilen uygulama, tüm ekiplere tanıtımının yapılmasının ardından 2015 yılı Kasım ayından 2016 yılı Ocak ayına kadar kullanıma sunulmuştur. Ekipler tarafından birbirlerine yönlendirilmiş olan olay kayıt sayıları, uygulamanın kullanılmasından önceki ve kullanıldıktan sonraki HPSM üzerinden sayısal veri olarak çekilmiştir (Tablo 1). Çekilen verilere bakıldığında, geliştirilen uygulamanın kullanımı sayesinde aksiyon alması gereken ekibin olay kaydını başka ekibe yönlendirme gereksiniminde azalma olduğu ve ihtiyaç duyulan bilgilere uygulama 
üzerinden ulaşılabildiği gözlenmiştir. Tablo 2'de ekiplere aylık olarak açılan olay kayıtları temel alınarak hesaplanan, diğer ekipler tarafından iletilen ve uygulamanın kullanımından sonraki olay kayıt sayılarının yüzdeleri gösterilmektedir.

Uygulamanın tamamlanmasının ardından kullanıcılara hangi modülden hangi bilgilere ulaşabilecekleri detaylı bir biçimde anlatılmıştır. Akabinde kullanıcı testlerine başvurulmuştur. Uygulamanın ekipler üzerindeki etkisini ölçmek ve istenilen faydanın ne derece sağlandığı konusunda bilgi edinmek amacıyla ekiplerden diğer ekiplere yönlendirilmeyen olay kayıt sayılarının tutulması sağlanarak bir liste elde edilmiştir. Bu liste sayesinde Tablo 3 'te bir aylık süreç içerisinde takibi yapılan, her bir ekibin diğer ekiplere yönlendirdiği ve yönlendirmediği olay kayıt sayıları elde edilmiştir.

Tablo 1. Uygulama Öncesi ve Sonrası Ekipler Arası Yönlendirilen Olay Kayıt Sayıları

\begin{tabular}{|c|c|c|c|}
\hline AKTARIM & $\begin{array}{c}\text { Kullanım Öncesi } \\
\text { (50 iş günü) }\end{array}$ & $\begin{array}{c}\text { Kullanım Sonrası (50 iş } \\
\text { günü) }\end{array}$ & Azalma Oranı \\
\hline xDSL -> IYS & 410 & 163 & $\% 60$ \\
\hline xDSL -> TMS & 465 & 276 & $\% 40$ \\
\hline TMS -> IYS & 141 & 87 & $\% 38$ \\
\hline TMS -> xDSL & 430 & 311 & $\% 0$ \\
\hline IYS -> TMS & 130 & 129 & $\% 27$ \\
\hline IYS -> xDSL & 298 & 216 & \\
\hline
\end{tabular}

Tablo 2. Uygulama Öncesi ve Sonrası Tüm Olay Kayıt Sayısı İçerisindeki Yönlendirme Yüzdeleri

\begin{tabular}{|l|c|c|}
\hline \multicolumn{1}{|c|}{ AKTARIM } & $\begin{array}{c}\text { Kullanım } \\
\text { Öncesi (50 is günü) }\end{array}$ & $\begin{array}{c}\text { Kullanım } \\
\text { Sonrası (50 iş günü) }\end{array}$ \\
\hline xDSL -> IYS & $16 \%$ & $7 \%$ \\
\hline xDSL -> TMS & $18 \%$ & $11 \%$ \\
\hline TMS -> IYS & $6 \%$ & $3 \%$ \\
\hline TMS -> xDSL & $18 \%$ & $12 \%$ \\
\hline IYS -> TMS & $12 \%$ & $12 \%$ \\
\hline IYS -> xDSL & $26 \%$ & $24 \%$ \\
\hline
\end{tabular}

Tablo 3. Ekipler Arası Aylık Etkilenen Olay Kayıt Sayıları

\begin{tabular}{|l|c|c|c|}
\hline \multicolumn{1}{|c|}{ AKTARIM } & Gönderilenler & Gönderilmeyenler & Toplam \\
\hline xDSL -> IYS & 163 & 165 & 328 \\
\hline xDSL -> TMS & 276 & 127 & 403 \\
\hline TMS -> IYS & 87 & 3 & 90 \\
\hline TMS -> xDSL & 311 & 20 & 331 \\
\hline IYS -> TMS & 129 & 0 & 129 \\
\hline IYS -> xDSL & 202 & 14 & 216 \\
\hline
\end{tabular}

\section{TARTIŞMA VE SONUÇ}

Sonuç olarak bir problemin varlığından yola çıkılarak mevcut sistemde süreci iyileştirmek ve bilgi yönetiminin doğru bir biçimde kullanılabilmesi adına gerçekleştirilen uygulama ile operasyon hizmetinin etkinliğinin arttı̆̆ görülmektedir. Sistem Geliştirme Yaşam Döngüsü çerçevesinde geliştirilen uygulamanın problem tespit aşamasından başlayarak gereksinimler belirlenmiş olup ihtiyaç analizi yapılmıştır. İhtiyaçların belirlenmesi adına 


\section{INFOั}

ISSN: 2602-3563

Görüşme ve Kaynak Tarama tekniklerinden faydalanılmıştır. Uygulama içerisindeki modüllerin kullanılabilirliğinin fazla olması adına data düzeltmesi gerektirmeyen, kronik hale gelen bilgi taleplerinin karşılanması öngörülmüştür. Bu sayede kronik durumda olan olay kayıtları için aksiyonun alınacağı ekip tarafından farklı bir ekibe yönlendirme yapılmadan sonuçlanmasını sağlayan bir platform hedeflenmiştir. Bunun akabinde sistem tasarımı yapılmış ve yazılım geliştirilmiştir. Erken test etmenin önemli olduğu günümüz yazılım projelerinde her modül tasarımının ardından yazılım testleri gerçekleştirilmiş ve gerekli düzeltmelerin sağlanmasının ardından uygulama kullanılmaya başlanmıştır. Bu doğrultuda olay yönetimi çerçevesindeki olay kaydı çözüm süresinin kısaltılabildiği ve SLA kapsamında kararlaştırılmış olan sürenin aşılmadan gerekli aksiyonların hızlı bir şekilde alınabildiği saptanmıştır. Dolayısıyla, BTK şikayetlerinin sayısında azalma olacağı öngörülebilmektedir.

Yönetim Bilişim Sistemi; yöneticiler ve çalışanların bakış açısına göre zamanlı ve istenilen nitelikte bilgiye ulaşıma imkan sağlayan, hizmet kullanıcıları ve diğer dış çevre bakış açısına göre ise işlem, süreç ve hizmetlerin hızlı, kaliteli ve etkin şekilde ulaşılmasına yardımcı olan bir sistemdir (Yönetim Bilişim Sistemleri, 2017). Yönetim Bilişim Sistemi kapsamında ortaya atılan ve iyileştirmeye yönelik yapılan bu çalışmada, işletmelere ve işletmelerin müş̧erilerine değer yaratmak için; insan, süreç ve teknoloji içeren sistemleri yapılandırmak ve işletmek için bilgisayar ve iletişim teknolojileri bir arada gerçekleştirilerek bu uygulama geliştirilmiş̧tir.

\section{KAYNAKLAR}

Agile, 2015, Scrum. http://www.acm-software.com/scrum/, (20.08.2015).

Altun, D., 2006, “Türk Telekomünikasyon A.Ş. İl Telekom Müdürlüklerinin Veri Zarflama Analizi ile Etkinlik Ölçümü̈’. (Yayınlanmamış Yüksek Lisans Tezi). Ankara: Gazi Üniversitesi Fen Bilimleri Enstitüsü.

Atmaca, G., 2012, “Agile neden ortaya çıktl, geleneksel yöntemlerden ne farkl var?”, https://www.kocsistem.com.tr/tr/ksblog/Sayfalar/agile-yaklasimi-ve-scrum-yonetimi.aspx, (08.08.2015).

Aydın, C., Tarhan, C. ve Tecim, V., 2015, "IT Based Vehicle Tracking System for Effective Management in Public Organizations", Procedia Economics and Finance, 33 (2015) 506 - 517. https://doi.org/10.1016/S22125671(15)01733-5.

Baytam, V., 2011, "Scrum Yazılım Geliştirme Metodolojisi İ̧̧in Yönetim Sistemi Tasarımı ve Gerçeklenmesi”. (Yayınlanmamış Yüksek Lisans Tezi). İstanbul: Yıldız Teknik Üniversitesi Fen Bilimleri Enstitüsü.

Beyler, A., 2014, “Türk Telekom Il Türk Telekom Müdürlüklerinin Veri Zarflama Analizi Yöntemi ile Performans Değerlendirmesi”. (Yayınlanmamış Yüksek Lisans Tezi). İstanbul: Fatih Üniversitesi Fen Bilimleri Enstitüsü.

Cyberethics, 2015, “Internet kullanıminın faydalart". http://www.cyberethics.info/cyethics1/ index.php?option=com_content\&view=article\&id=186\&Itemid=83\&lang=tr, (14.11.2015).

Çakal, R., 1996, "Doğal Tekellerde Özelleştirme ve Regülasyon". http://www.bilgitoplumu.gov.tr/wpcontent/uploads/2014/04/Recep-Cakal_Doga_Tekellerde_Regulasyon.pdf, (14.11.2015).

Demir, S.Y., 2015, "Meslek Liseleri için Web Tabanlı Staj Yönetim Sistemi Tasarımı ve Uygulaması", (Yayınlanmamış Yüksek Lisans Tezi). İzmir: Dokuz Eylül Üniversitesi Sosyal Bilimler Enstitüsü.

Demirhan, D., 2002, “İsletmelerde Stratejik Bilgi Sistemleri Yönetimi ve Rekabet Üstünlüğ̈̈ Elde Edilmesindeki Rolü”, http://www.acarindex.com/dos yalar/makale/ acarindex-1423877185.pdf, (21.09.2015).

Demiroğ, E., 2012, “Yazllım Devi". http://www.yazilimdevi.com/Makaleler-864-scrum-ogreniyorum-serisi-1-scrum-nedir-nicin-gereklidir.aspx, (01.07.2015).

Ekergil, V., 2005, “Telekomünikasyon Sektöründe Maliyetleme ve Maliyete Dayalı Fiyatlandırma Yaklaşımları: Türk Telekomünikasyon A.Ş. İçin Bir Model Önerisi”. (Yayınlanmamış Doktora Tezi). Eskişehir: Anadolu Üniversitesi Sosyal Bilimler Enstitüsü. 
Hazer, M., 2008, “Agile Yazllım Geliştirme ve Scrum". http://mhazer.blogspot.com.tr/2008/10/agile-yazlmgelitirme-ve-scrum.html, (02.08.2015).

Karlıdere, T., Kalıpsız, O., 2003, “Yazılım Mühendisliği Projelerinde Çevik Yaklaşımların Yeri”. 1.Ulusal Yazılım Mühendisliği Sempozyumu- p.205-212. http://www.emo.org.tr/ekler/39e76be5fe76133_ek.pdf, (15.08.2015).

MEB, 2012, “Etkileşimli Web Uygulamalarına Giriş". http://ayrancicpl.meb.k12.tr/meb_iys_dosyalar/70/02 /320095/dosyalar/2014_10/07102925_etkilesimliwebuygulamalarinagiris.pdf, (08.10.2015).

Oktav, M., Kavas, A., Önce, G., Tanyeri, M., 1990, “Orta ve Küçük İşletmelerde İhracata Yönelik Pazarlama Sorunlarl ve Çözüm Önerileri”. Ankara: TOBB Yayınları.

Oral, S., 2012, "Microsoft Visual Studio Nedir? Ne Amaçla Kullanılır?" http://www.mshowto.org/microsoftvisual-studio-nedir-ne-amacla-kullanilir.html, (15.09.2015).

Öztürk, M., 2012, “Uzaktan Eğitimde Ölçme Değerlendirme Sistemi Tasarımı ve Yazılım Test Teknikleri ile Performans Analizi”. (Yayınlanmamış Yüksek Lisans Tezi). Sakarya: Sakarya Üniversitesi Fen Bilimleri Enstitüsü.

Süloğlu, S., 2005, "Yöntem Çevik Olunca". 2.Ulusal Yazılım Mühendisliği Sempozyumu. http://www.emo. org.tr/ekler/401bb41f7e78637_ek.pdf, (16.08.2015).

Şahin, E., Keskin Kaynak İ., Koç, H., 2013, CMMI-DEV Seviye-3 Sertifikasyonuna Sahip Bir Organizasyonda SCRUM Çevik Yazılım Geliştirme Yöntemi’nin Yazılım Geliştirme Çalışmalarında Uygulanması. http://ceurws.org/Vol-1072/submission8 .pdf, (07.08.2015).

Türk Telekom Veri Merkezi, 2015, https://www. ttvm.com.tr/ttvmwp.web/idc/index.xhtml, 20.06.2015.

Vikipedi, 2015, “Microsoft Visual Studio”. https://tr.wikipedia.org/wiki/Microsoft_Visual_Studio, 04.09.2015.

Yazılım Her Yerde, 2014, "Agile Metodolojisi \& Scrum". http://www.yazilimheryerde.com /2014/09/agilemetodoloji-scrum.html, (17.08.2015).

Yönetim Bilişim Sistemleri, 2017, https://berkayvaz.files.wordpress.com/2013/04/yc3b6netim-bilic59fimsistemleri-final-notlari.pdf, 10.10.2016 